\title{
Interfaces entre território, ambiente e saúde na atenção primária: uma leitura bioética
}

José Roque Junges ${ }^{1}$, Rosangela Barbiani ${ }^{2}$

\section{Resumo}

Os desafios éticos da saúde pública são atravessados por determinantes macro e microssociais, exigindo que o serviço esteja focado no território de abrangência e nas necessidades de sua respectiva população. Por isso, entender as interfaces entre território, ambiente e saúde é importante. Território é o espaço das sociabilidades cotidianas do grupo social que o habita, não reduzido aos limites administrativos. Saúde depende tanto do micro território quanto do macro ambiente natural e societário, pois ambos configuram os determinantes sociais da reprodução da vida. Assim, o primeiro desafio ético é a construção de um modelo de atenção que integre cuidados primários e conhecimentos da vigilância sobre as necessidades em saúde daquele território. Outro, é a construção de ações intersetoriais politicamente articuladas e pactuadas para enfrentar os determinantes sociais e os danos ambientais que afetam a saúde daquela população no sentido da melhoria de sua qualidade de vida.

Palavras-chave: Bioética. Saúde pública. Atenção básica à saúde. Vigilância em saúde. Território. Ambiente. Determinantes sociais da saúde.

\section{Resumen}

\section{Las interfaces entre territorio, ambiente y salud en la atención primaria: una lectura bioética}

Los desafíos éticos de la salud pública están atravesados por determinantes micro y macro sociales, exigiendo que el servicio esté enfocado en el territorio de abarcamiento y en las necesidades de su respectiva población. Por eso entender las interfaces entre territorio, ambiente y salud es importante. Territorio es el espacio de las sociabilidades cotidianas del grupo social que lo habita, no reducido a los límites administrativos. Salud depende tanto del micro territorio, cuanto del macro ambiente natural y societario, ya que ambos configuran los determinantes sociales de la reproducción de la vida. Así, el primer desafío ético es la construcción de un modelo de asistencia que integre cuidados primarios y los conocimientos de la vigilancia sobre las necesidades en salud de aquel territorio. Otro desafío ético es la construcción de acciones inter-sectoriales políticamente articuladas y acordadas para enfrentar los determinantes sociales y los daños ambientales que afectan la salud de aquella población en el sentido de mejorar su calidad de vida.

Palabras-clave: Bioética. Salud pública. Atención primaria de salud. Vigilancia en salud. Territorio. Ambiente. Determinantes sociales de la salud.

\section{Abstract \\ Interface between territory, environment and health in primary care: a bioethics approach}

Ethic challenges of public health are traversed by micro and macro social determinants, requiring the health service to be focused on the scope and its population's needs. Therefore understanding the interface between territory, environment and health is important. Territory is the space of the daily sociability of the social group who inhabit it, not reduced to administration limits. Health depends both on the micro territory and the macro natural and social environment, since represent the social determinants of life reproduction. So, the first ethic challenge is the construction of an assistance model which integrates primary care and the surveillance knowledge on the health needs of this territory. Another challenge is to build intersectoral actions, politically jointed and compromised to face social determinants and environmental damages that affect the health of population, improving their life quality.

Key words: Bioethics. Public health. Primary care service. Health surveillance. Territory. Environment. Health social determinants.

1. Doutor roquejunges@hotmail.com 2. Doutora barbiani@unisinos.br - Universidade do Vale do Rio dos Sinos (Unisinos), São Leopoldo/ RS, Brasil. 
De longa data os conflitos éticos da clínica hospitalar estão sendo refletidos pela ética médica e, mais recentemente, pela bioética clínica, tendo como diretrizes predominantes os tradicionais princípios da bioética e as normas do Código de Ética Médica (CEM). Convencionou-se chamar de principialismo a tendência bioética de solucionar os casos pela aplicação dos princípios - que recebeu críticas pela pouca atenção ao contexto social e às circunstâncias concretas do caso particular. Devido à diferença entre a lógica da clínica hospitalar e a lógica da clínica ampliada da atenção primária não se pode pensar os problemas éticos dessa última no paradigma da primeira, pois ambos se caracterizam por uma especificidade própria ${ }^{1}$.

$\mathrm{Na}$ atenção primária, as necessidades em saúde e os problemas éticos, decorrentes da tentativa de dar resposta a elas, estão sempre fundamentalmente atravessados e configurados pela subjetividade do usuário e do profissional e pelo seu território ambiente e respectivos contextos socioculturais. Por isso, a realidade da atenção primária exige uma ética hermenêutica que interprete e reflita criticamente a partir da própria facticidade do contexto em que acontecem os problemas éticos, configurando-os como desafios éticos - base para encontrar os caminhos de solução.

Aqui, faz-se necessário ter presente a diferença entre conflitos éticos que muitas vezes ocorrem na clínica hospitalar em que existe um conflito entre diferentes soluções possíveis (p. ex., desligar ou não os aparelhos que mantêm alguém vivo, mas já em processo de morte). Para resolvê-los, é preciso considerar os princípios e deveres implicados no caso. Desafios éticos ordenam respostas amplas que não são claras à primeira vista, exigindo hermenêutica, muita discussão e pactuação coletiva para encontrar o caminho de responder à exigência implícita no desafio, por tratar-se de realidades a construir (p. ex., como atender longitudinalmente usuários em condições crônicas).

A resposta a esse desafio - ético - não depende primariamente de deveres ou normativas, mas de bens e valores a ela implicados, demandando a hermenêutica do contexto. Na maioria das vezes, essa resposta tem uma dimensão coletiva. A atenção primária lida mais com desafios éticos do que com conflitos éticos. Como resultado, suas demandas de resposta são mais pragmáticas do que dramáticas ${ }^{2}$, haja vista que ela comporta mais desafios do que conflitos éticos. A respeito, o presente artigo assume essa compreensão da bioética da atenção primária.

A atenção primária surgiu para responder à visão ampliada das necessidades em saúde, sendo o ponto de referência para pensar qualquer ética dos cuidados primários. Todos os problemas e desafios éticos emanam dos processos de trabalho e da organização do sistema de resposta a essas necessidades em determinado território e ambiente.

As necessidades são experimentadas individualmente e determinadas por seu contexto, mas precisam ser pensadas e organizadas no coletivo, pois nele acontece a demanda que as configura socialmente. A ida ao serviço para buscar resposta a uma necessidade determina a demanda e desencadeia processos de trabalho na tentativa de responder a essa necessidade situada. No vigente modelo de atenção primária a responsabilidade por esses processos pertence à equipe, e não apenas ao profissional. Essa lógica de trabalho exige nova subjetividade profissional que emerge de um modelo de formação e educação da saúde pautado em competências como a participação democrática e a cogestão, porque as práticas precisam ir além da responsabilidade clínica, alcançando o âmbito da responsabilidade sanitária.

Essas duas determinações da lógica da atenção primária - necessidades individuais em saúde que precisam ser respondidas no território e no coletivo e processos de trabalho organizados em equipe para a elas responder - apontam para uma possível configuração da ética relativa à solução dos desafios éticos que podem surgir na atenção primária.

Considerando a especificidade desse nível de atenção à saúde e a centralidade que assume na efetivação do sistema de saúde, este artigo objetiva apontar e refletir sobre os desafios éticos que constituem, sobretudo, a interface entre território, ambiente e saúde. Este objetivo geral desdobra-se, por um lado, na discussão sobre o desafio de repensar em equipe um modelo de atenção que contemple essa interface e, por outro, na necessidade de construir ações intersetoriais para responder às necessidades em saúde daquele território. Para dar resposta a esses objetivos dois conceitos são centrais: a compreensão ecossistêmica de saúde que surge da interface entre território, ambiente e saúde, apontando para o modelo da vigilância em saúde, e a visão da justiça ambiental que surge da constatação dos determinantes sociais da saúde, exigindo políticas intersetoriais para além do setor saúde. 
Território como espaço das sociabilidades cotidianas

Na geografia tradicional, no sentido jurídicopolítico o território sempre foi entendido como espaço limitado pelas estruturas de poder ${ }^{3}$. Por isso, correspondia à área delimitada pelas fronteiras de um país, estado, município ou distrito. Os limites artificialmente determinados respondiam a critérios de controle administrativo - contudo, faz-se necessário ressaltar que território também compreende o sentido etológico, aludindo ao espaço necessário para a sobrevivência animal.

A nova geografia está centrada numa concepção de território construído pelas inter-relações e intercâmbios do cotidiano social de determinada sociedade como espaço simbólico de significados. Este é o conceito de espaço proposto pelo geógrafo brasileiro Milton Santos ${ }^{4}$ como um conjunto indissociável de sistemas de objetos (fixos) e de ações (fluxos) que se apresentam como testemunhas de uma história escrita de processos do passado e do presente. Sobre um ambiente natural os grupos sociais humanos deixam as suas marcas em estruturas materiais fixas e em vias de circulação e de fluxos que constroem o espaço simbólico das sociabilidades cotidianas e das identidades socioculturais. 0 território usado identifica-se com o espaço geográfico socialmente organizado. Portanto, território é um espaço social, real e objetivo, atravessado por valores e significados culturais da subjetividade, não tendo limites definidos, por caracterizar-se por sua dimensão simbólica, não identificada com critérios territoriais administrativos ${ }^{4}$.

Considerando o exposto, o território assim constituído é o lugar da construção e do funcionamento das redes de apoio social da comunidade que habita esse território apropriado. Fazer parte desse espaço das sociabilidades cotidianas configura-se fator que determina a identidade dos habitantes como um grupo específico e que define as competências para participar das redes e aceder aos serviços oferecidos por esse espaço social simbólico.

Pensar o território nessa perspectiva implica atribuir-lhe identidade intrínseca à constituição da vida social, seja no âmbito da organização dos poderes, seja nas formas de produção e distribuição das riquezas. As condições de moradia e de ocupação dos territórios nas mais diversas configurações socioambientais são produtos das relações entre desenvolvimento econômico e social, dos quais de- rivam os demais indicadores de qualidade de vida de dada população. Indicadores esses que traduzem o nível de atendimento às necessidades básicas da vida, que precisam ser equacionadas na relação Estado-sociedade, por meio de políticas públicas e de mecanismos de regulação social. Dentre as necessidades básicas, a saúde comparece como uma das mais essenciais, tendo em vista sua permeabilidade e influência não só nos perfis sociodemográficos populacionais, mas, sobretudo, no potencial de desenvolvimento societário.

O território socialmente configurado determina a situação sanitária da população que o habita, sendo a saúde dialeticamente ligada e determinada por esse espaço social, possibilitando o surgimento de redes sociais de apoio e convivência. Por consequência, uma compreensão integral da saúde incluirá as condições espaciais para a reprodução social da vida ou para a promoção da qualidade de vida, pois o espaço social oferece os apoios, recursos e ferramentas para reagir a qualquer quebra do equilíbrio vital. Assim, saúde é resiliência ou capacidade de reação - dependendo essencialmente do ambiente coletivo que constitui o espaço geográfico.

Sob tal ótica, os serviços do sistema de saúde precisam funcionar em interação com esse espaço social. A efetividade do acesso e da resposta às necessidades dependerá de sua inserção no espaço das sociabilidades cotidianas dos usuários, que não se identifica simplesmente com a definição administrativa de território. Só assim será possível detectar contextos de vulnerabilidade e coletar dados epidemiológicos efetivos sobre a situação sanitária daquela comunidade. Por isso, o conceito de território na gestão e na prática de saúde sempre adquiriu maior importância ${ }^{5}$, seguindo as intuições de Santos ${ }^{6}$ acerca do espaço geográfico e fomentando o surgimento de novo campo de conhecimento na interface entre geografia e saúde ${ }^{7}$.

Essa compreensão manifesta-se, por exemplo, nos territórios das equipes de Estratégia de Saúde da Família (ESF), entendidos como espaço das sociabilidades cotidianas dos usuários e não como adscrição territorial definida por critérios numéricos e administrativos. A atenção ao ambiente é uma das características da estratégia e um dos papéis dos agentes comunitários. Esse ambiente é menos o ecossistema natural do que o espaço apropriado pelo uso social por parte de atores e projetos que configuram esse território da população atendida. Essa apropriação responde a interesses muitas ve- 
zes antagônicos, gerando conflitos que externalizam custos ambientais e sociais incidentes sobre a saúde dos usuários daquele território. Essa íntima interação entre saúde e espaço geográfico exige pensar o ambiente como lugar da reprodução social da vida, e a saúde sob uma ótica ecossistêmica.

\section{Ambiente e reprodução social da vida}

No tocante às relações entre a saúde e as condições de vida, o sanitarista argentino Juan Samaja ${ }^{8,9}$ entende o ambiente como lugar de reprodução social da vida. Para ele, as ciências da saúde têm por objeto os encontros e transações entre diversos espaços de valorações e regulações dos problemas que a reprodução social apresenta em todas as esferas da sociabilidade humana: biossocial, sociocultural, econômico-societal e a ecológica-política ${ }^{10}$.

Segundo a perspectiva de Samaja, o objeto saúde compreende tanto as concepções e práticas sanitaristas das esferas 'biocomunal' (reprodução biológica e ambiental); 'comunal-cultural' (reprodução da consciência e da conduta); 'societária' (reprodução associativa e econômica) e; 'estatal' (reprodução ecológico política). Esse foco da saúde na reprodução social das condições de vida ultrapassa o puro espaço disciplinar da medicina, obrigando englobar uma epidemiologia ecológica, antropológica, sociológica, jurídica, econômica e ambientalista ${ }^{11}$. Para Samaja, as condições de vida determinam as situações de saúde. Portanto, sob sua interpretação, as situações de saúde devem ser estudadas na perspectiva das condições de vida. Isso significa dizer que se a saúde na definição da OMS é o completo estado de bem-estar, então ela é inseparável das condições de vida, e só se pode defini-la como controle sobre os processos de reprodução da vida social. Ou seja, a saúde constitui a própria ordem regular desse movimento reprodutivo ${ }^{12}$.

A compreensão de ambiente como lugar das condições para a reprodução social da vida, proposta por Samaja, é uma ampliação em dimensão macro do que é dito em micro em relação ao território como espaço da sociabilidade cotidiana, porque, além do natural, ambiente engloba a ambiência cultural, societária e política. Esta é a diferença entre território socialmente usado e organizado e ambiente como lugar amplo das condições de vida. A saúde e a qualidade de vida dependem tanto do território atravessado pelo cotidiano social quanto o ambiente amplo da reprodução social da vida.
Para entender o ambiente como o conjunto de condições para a reprodução social da vida é oportuno introduzir o conceito de capital social em suas relações com a saúde. Para Bourdieu, capital social é o agregado de recursos potenciais ou atuais, relacionados com a possessão de uma rede duradoura de relações mais ou menos institucionalizadas de aquisição e reconhecimento mútuos, ou em outras palavras, de participação num grupo que oferece, a cada um dos seus membros, o reconhecimento do capital possuído pela coletividade, dando-lhes credencial que os capacita socialmente nos diversos sentidos da palavra ${ }^{13}$.

O capital social compreende dois aspectos: o dinamismo social das redes de apoio de uma comunidade e o credenciamento que a comunidade oferece aos seus membros para a participação social. Portanto, na perspectiva de Bourdieu, sem redes sociais consistentes e dinâmicas não existe credenciamento e capacitação dos membros para relações sociais participativas. Os dois sentidos de capital social estão intimamente relacionados: como dinamismo das redes de apoio social (processo) e como credenciamento para a participação social (produto).

Capital social conecta as pessoas, de modo que pode tornar relacionamentos em fonte de recursos para o bem comum. Enquanto a desagregação social acarreta atitudes que servem apenas a metas individuais, a coesão social ocasiona modos de proceder que beneficiam o todo. Comunidades coesas são mais prováveis de apoiar um ambiente que facilite a adoção de comportamentos saudáveis e o acesso a recursos que permitam maior qualidade de vida. Daí decorre a importância da compreensão do termo capital social para a ESF, porque reconhece a importância de redes sociais, normas de reciprocidade, assistência mútua e confiança. Cada comunidade possui um conjunto de normas e crenças que podem servir para criar e sustentar políticas. Redes de promoção de saúde geradas com a participação comunitária melhoram a autoeficácia e a confiança das pessoas em suas habilidades para agir. Permitem às pessoas tomar decisões conjuntas e negociar com os pares ${ }^{14}$.

Na perspectiva do capital social, saúde e ambiente estão intimamente entrelaçados, pois o ambiente identifica-se com o espaço social das relações e condições de vida que possibilitam a reprodução social da saúde. A falta de capital social determina um ambiente que não propicia as condições para o acesso aos recursos necessários à qualidade de vida e saúde. Essa íntima interação entre saúde e ambiente social conduz a uma compreensão ecossistêmica da própria saúde. 


\section{Compreensão ecossistêmica da saúde}

O paradigma ecológico é uma crítica do reducionismo científico, que fragmenta a percepção e impede uma visão sistêmica do ambiente, com sua história de efeitos sobre a própria compreensão da saúde humana. A relação da saúde com o ambiente sempre foi uma preocupação e por muito tempo respondeu pela causa das doenças na compreensão miasmática. A doença era compreendida como um reflexo dos miasmas presentes no ambiente. Tratava-se de uma explicação essencialmente ambiental da doença ${ }^{15}$.

A revolução bacteriana mudou radicalmente essa concepção, porque as doenças não são provocadas por ares pestilentos, mas sim por micróbios que se alojam no corpo do enfermo. $\mathrm{O}$ ambiente continua a ser importante como lugar em que habitam os vetores que transmitem as patologias. A doença não é veiculada pelo miasma, mas pelo contágio dos micróbios daquele ambiente. Assim surge a ecologia médica, que vai estudar a inter-relação entre o ambiente e os vetores das patologias ${ }^{16}$.

A revolução bacteriana e a consequente ecologia médica trouxeram grandes benefícios à humanidade, mas também um efeito colateral negativo: 0 retrocesso no pensamento da medicina social - efeito que até hoje contamina a biomedicina. As novas doenças civilizacionais não têm uma origem microbiana, adquirindo o ambiente nova importância não apenas como reservatório, mas como um ecossistema de interdependências naturais, sociais, políticas e culturais que influenciam a saúde e a doença ${ }^{15}$.

A virada microbiana fomentou a perspectiva campanhista da saúde pública que lutava pela erradicação das doenças transmitidas por contágio por meio da descontaminação dos ambientes, sem atentar para o contexto social de pobreza e de falta de saneamento das populações acometidas. Tratava-se de livrar o ambiente dos micróbios, sem olhar para as condições sociais de vida das populações que o habitavam. A atual proliferação de doenças crônicas não transmissíveis de cunho civilizacional obriga a novamente considerar o contexto social e cultural dos processos de adoecimento.

Para fazer frente a esse desafio, surge a compreensão ecossistêmica da saúde proposta por Minayo ${ }^{17}$. Há uma mudança de foco nesta concepção, porque o espaço socioambiental não é algo exterior que condiciona lateralmente o processo saúdedoença, mas algo que essencialmente faz parte da própria compreensão de saúde. Essa concepção transforma a visão sobre os riscos e agravos à saúde, porque passa a incluir o ambiente como algo fundamental para a produção das condições sociais de reprodução da vida - daí se conjugam a sustentabilidade ambiental e o desenvolvimento social como bases para entender a saúde como qualidade de vida.

Isso significa, segundo Minayo, um processo de construção de novas subjetividades pela participação em projetos de mudanças em uma ótica de desenvolvimento sustentável e de cumplicidade com as gerações futuras. Embora existam tentativas de quantificar indicadores (...) A definição de qualidade de vida é eminentemente qualitativa, pois junta, ao mesmo tempo, o sentimento de bem-estar, a visão de finitude dos meios para alcançá-lo e a disposição para a solidariedade, ampliar as possibilidades presentes e futuras ${ }^{18}$. Dessa maneira, o enfoque ecossistêmico de saúde como qualidade de vida é como um guarda-chuva onde estão ao abrigo nossos desejos de felicidade, nossos parâmetros de direitos humanos; nosso empenho em ampliar as fronteiras dos direitos sociais e das condições de ser saudável e de promover saúde ${ }^{18}$.

A partir dessa compreensão ecossistêmica da saúde reforça-se a necessidade da construção de modelos de atenção à saúde que englobem o território ambiente na programação das ações sanitaristas e na organização dos processos de trabalho e suas respectivas práticas nos serviços de atenção básica. Esse modelo identifica-se com a vigilância em saúde que tem como foco de suas ações as necessidades em saúde de um território específico habitado por grupos populacionais definidos - foco que se torna preocupação ética das equipes na organização de suas práticas.

\section{Desafio ético da integração entre atenção bá- sica e vigilância em saúde}

A dimensão ética de qualquer ação exige autonomia para que o sujeito seja o seu protagonista e responsabilidade para que os resultados da ação sejam reconhecidos como próprios. Para oportunizar a autonomia e a responsabilidade nas práticas de atenção básica faz-se necessário refletir e tomar consciência do paradigma de pensar e agir em saúde - no qual se movem essas práticas. Por isso, a importância de discutir o paradigma, expresso no modelo de atenção que organiza os processos de trabalho, porque essa tomada de consciência possibilita autonomia e responsabilidade no agir com implicações éticas para as práticas. 
Morin ${ }^{19}$ chama os bastidores do pensamento de paradigma que contém para todos os discursos que se realizam sob seu domínio os conceitos fundamentais ou as categorias mestras de inteligibilidade, ao mesmo tempo, o tipo de relações lógicas de atração/repulsão (conjunção, disjunção, implicação ou outras) entre esses conceitos e categorias. Assim, o paradigma contém, por um lado, as categorias de inteligibilidade que determinam a formulação de ideias no discurso e, por outro, as operações lógicas que definem a inclusão ou exclusão de conhecimentos de acordo com a concepção de verdade presente no paradigma. Mas o paradigma é vazio e sem conteúdo, porque nunca é formulado nem está inscrito em nenhuma parte. É sempre virtual. Só existe nas suas atualizações e nas suas manifestações. Só existe 'paradigmaticamente', no exemplo que assinala a sua paternidade ${ }^{20}$.

Por isso, tornar explícito e consciente pelo conhecimento o que está implícito e inconsciente no paradigma faz parte de uma atitude ética em relação ao conhecer e ao agir, determinando a configuração dos saberes e práticas. Aceitando que todo conhecimento é paradigmaticamente situado, pode-se ter clarividência sobre as condições em que se usam conhecimentos e se desenvolvem determinadas ações. Só assim pode haver posicionamento ético frente às práticas. Essa clarividência educa para a avaliação contínua e a permanente busca de melhores soluções. A compreensão acerca de um paradigma aponta ao mesmo tempo para as possibilidades dos saberes e das práticas, mas igualmente para os seus limites. A incerteza e a necessidade da avaliação integram a própria prática, porque sempre existe a possibilidade de ilusões e contradições. A ética exige dar-se conta das possibilidades e dos limites dos saberes e práticas. Isso só é possível quando o indivíduo toma consciência do paradigma no qual se move ao conhecer e agir ${ }^{21}$.

Essa constatação sinaliza para a necessidade de se discutir os paradigmas e modelos de atenção à saúde nos coletivos de trabalhadores como exigência ética da avaliação. A promoção desta discussão se configura tarefa primordial das equipes e dos gestores, tendo em vista que estes não podem ficar reduzidos à execução administrativa do sistema, mas sim como promotores da cogestão dos trabalhadores. Só assim se viabiliza o protagonismo nos processos de trabalho e a corresponsabilidade da equipe de saúde em relação aos usuários, porque eles se tornam sujeitos de suas práticas e não puros executores de procedimentos aplicados automaticamente sem tentar compreender as necessidades e problemas de saúde. Mas a superação do automatismo dos procedimentos só é possível com a autonomia criada pela consciência do paradigma e modelo no qual o trabalhador se move, geradora de competências para decisões criativas e adaptadas à subjetividade do usuário.

Com a implementação do Sistema Único de Saúde (SUS), as noções de território, bem como a de redes integradas de cuidados, tornaram-se princípios organizadores dos processos de trabalho, especialmente na política de atenção básica. Esses processos de trabalho dependem dos modelos de atenção que se referem ao modo de organizar os serviços de saúde tendo presente o uso de diferentes tecnologias nas práticas de cuidado. No modelo de atenção que tem como foco o território ambiente e como consequência uma visão ecossistêmica de saúde, a vigilância torna-se o nó górdio da organização do serviço, porque o conhecimento produzido pela vigilância sobre as necessidades em saúde daquele território torna-se a base dessa organização - modelo que nas portarias do ministério recebe a denominação de vigilância em saúde ${ }^{22}$. Essa corrente de organização da atenção à saúde enfatiza a criação de distritos sanitários para atender às necessidades e problemas de saúde específicos daquele local. Sua implantação depende da compreensão ecológica ou ecossistêmica da saúde e da reorganização das diferentes vigilâncias compartimentalizadas num modelo integrado com a atenção primária à saúde.

A Portaria 3.252 do Ministério da Saúde cria o Sistema Nacional de Vigilância em Saúde e pretende integrar as ações das diferentes vigilâncias, inserindo a vigilância na construção das redes de atenção à saúde, coordenadas pela atenção primária à saúde, como exigência da integralidade. $O$ artigo $1^{\circ}$ da portaria afirma: Vigilância em Saúde tem como objetivo a análise permanente da situação de saúde da população, articulando-se num conjunto de ações que se destinam a controlar determinantes, riscos e danos à saúde de populações que vivem em determinados territórios, garantindo a integralidade da atenção, o que inclui tanto a abordagem individual como a coletiva dos problemas de saúde ${ }^{22}$.

A integração com a atenção primária é premissa da nova concepção constante no artigo $6^{\circ} \mathrm{da}$ portaria: as ações de Vigilância em Saúde, incluindo a promoção, devem estar inseridas no cotidiano das equipes de Atenção Primária/Saúde da Família, com atribuições e responsabilidades definidas em território único de atuação, integrando os processos de trabalho, planejamento, programação, monitoramento 
e avaliação dessas ações ${ }^{22}$ - visão essa assumida pela nova Política Nacional de Atenção Básica ${ }^{23}$.

O modelo da vigilância em saúde pretende superar a pura sistematização de indicadores fornecidos, principalmente pela epidemiologia, para o planejamento e organização dos sistemas e serviços para se transformar numa reorganização das práticas a partir das necessidades em saúde. Nesse sentido, vai além da mera organização de distritos sanitários ${ }^{24}$ para enfatizar mais os processos de trabalho e as práticas de saúde na perspectiva da vigilância. Por isso, Paim afirma que a vigilância da saúde aponta na direção da superação da dicotomia entre as chamadas práticas coletivas, vigilância epidemiológica e sanitária; e as práticas individuais, assistência ambulatorial e hospitalar, por meio da incorporação das contribuições da geografia crítica, do planejamento urbano, da epidemiologia, da administração estratégica e das ciências sociais em saúde, tendo como suporte político-institucional o processo de descentralização e de reorganização dos serviços e das práticas de saúde em nível local ${ }^{25}$.

Assim, o modelo de vigilância em saúde pretende reorganizar o objeto de trabalho dos serviços de saúde, tendo por referência o território, os problemas de saúde e a prática intersetorial como formas de integrar a atuação dos diferentes setores da saúde sobre as complexas dimensões do processo saúde-doença, privilegiando sua determinação ecossocial com vistas a desenvolver novos modos de operacionalização do sistema de saúde. Tendo como foco o contexto territorial, o objeto do trabaIho consegue melhor definir os problemas de saúde e suas prioridades, de maneira mais articulada e integrada. Desse modo, a vigilância em saúde torna-se caminho para consubstanciar a integralidade ampliada e fazer acontecer a promoção da saúde. Pode-se também dizer que esse modelo tem forte identidade com os elementos que integram a ESF e representa forma significativa de fortalecimento dessa estratégia.

Portanto, o objeto do processo de trabalho em saúde são os problemas a serem conhecidos e as necessidades sociais de saúde da população a serem atendidas. Por isso, é importante a referência ao território, pois é no espaço de convivência social que os problemas e as necessidades recebem configuração específica - que é indispensável considerar na sua resposta. Nesse sentido, a vigilância em saúde agrega, aos enfoques clínico e epidemiológico que analisam os problemas e identificam as necessidades, o enfoque ecossocial que caracteriza o processo histórico de desenvolvimento econômico, social e político das populações, conformadores de seus problemas e necessidades. Isso significa que existe uma diversidade de objetos da vigilância em saúde, haja vista que os problemas e as necessidades exigem uma diversidade de ângulos e perspectivas. Ressalte-se que essa multiplicidade de objetos da vigilância em saúde é traduzida pela diversidade de sujeitos e variedade de ações necessárias ${ }^{26,27}$.

A assunção do modelo da vigilância em saúde acarreta mudanças no modo de encarar o objeto dos processos de trabalho e, por isso, configura-se como um desafio ético, pois se trata de mudança de atitude e de perspectiva nas práticas e nos serviços de saúde. $O$ que significa introduzir nos processos de trabalho as interfaces entre saúde e ambiente no território ambiente, por meio da questão da sustentabilidade, isto é, da criação de condições para a reprodução social da vida. Isso exige planejamento e avaliação contínuos para que a assunção desse modelo incentive novos modos de pensar e fazer saúde.

Desafio ético da integração entre determinantes sociais e sustentabilidade

A saúde coletiva, como campo de saberes e de práticas que conjuga conhecimentos das ciências da saúde e das ciências sociais, aborda a relação entre saúde e meio ambiente a partir de processos sociais e econômicos de desenvolvimento que conformam o território e impactam no meio ambiente sociocultural, determinando as condições para a qualidade de vida das populações. Essa visão baseia-se numa abordagem ecossocial da saúde, expressa na política da promoção da saúde e no modelo da vigilância em saúde. Para essa perspectiva, os determinantes sociais são essenciais para compreender a saúde e definir as práticas adequadas dos serviços ${ }^{28}$.

A Comissão Nacional sobre os Determinantes Sociais da Saúde (CNDSS) define os determinantes como fatores sociais, econômicos, culturais, étnicos/raciais, psicológicos e comportamentais que influenciam a ocorrência de problemas de saúde $e$ seus fatores de risco na população ${ }^{29}$. Existem diversas maneiras de entender como esses determinantes sociais afetam concretamente a saúde dos indivíduos. Este é o foco de discussão dessa visão, porque determina como devem ser encaminhadas as intervenções para fazer frente a esses determinantes sociais que condicionam a qualidade de vida das pessoas e engendram riscos para sua saúde ${ }^{30}$.

A Organização Mundial da Saúde (OMS) vem trabalhando intensamente na incorporação des- 
se modelo de conceber e planejar as políticas de saúde, desafiando os países a implementar padrões essenciais de saúde ambiental nos contextos de cuidados em saúde. Desenvolve protocolo de ações, discriminadas nos âmbitos nacional, distrital e local, incluindo desde a água potável e suficiente, saneamento básico, o conhecimento apropriado e aplicação de higiene e adequada ventilação até os recursos e financiamento para as ações e sensibilização de gestores, trabalhadores de saúde e comunidades ${ }^{31}$.

A partir das interfaces contidas no território ambiente versus saúde, que é a abordagem do presente artigo, e tendo presente a definição de determinantes sociais da CNDSS, pode-se dizer que os determinantes sociais conformam o território onde é tecida a sociabilidade cotidiana daquela comunidade. Nesse sentido, configuram as condições para a reprodução social da vida, que se expressam na saúde e qualidade de vida dos indivíduos que vivem naquele território ambiente. Dito de outra forma, o ambiente, como um dos determinantes da saúde e da própria sobrevivência, quando ameaçado compromete a saúde humana e a qualidade de vida de forma global e local.

Os processos socioeconômicos são um dos principais conformadores do meio ambiente, provocando em muitos casos danos que são empurrados para territórios onde habitam grupos sociais vulnerados por falta de força política e organizativa para reagir a esse metabolismo social da economia globalizada, externalizador dos seus custos para populações pobres. Esse fenômeno social configura o que se chamou de injustiça ambiental, que, associado aos mecanismos socioeconômicos de estratificação e distribuição desigual de riquezas, constituem determinantes sociais de iniquidades da saúde. Ambos afetam de forma perversa as comunidades periféricas, circunscrevendo grupos à situação de alto risco de exposição e vulnerabilidade social ${ }^{32}$.

O movimento social pela justiça ambiental ${ }^{33}$, introduzido no Brasil no Fórum Social de 2005, inspirou a criação da Rede de Justiça Ambiental, cujo fim precípuo é promover estudos e denúncias sobre situações de iniquidade ambiental que afetam populações pobres. A constatação dessas injustiças ambientais possibilita a articulação e a organização da população a não aceitar a degradação do seu meio ambiente, lutando por medidas socialmente igualitárias de política ambiental. Essa movimentação formulou o princípio ético de que grupos sociais vulneráveis não devem arcar com o peso desproporcional das consequências ambientais negativas resultantes de operações comerciais, industriais ou municipais ou da execução de políticas públicas e programas federais, estaduais, locais e tribais ${ }^{34,35}$.

A Rede de Justiça Ambiental define injustiça ambiental como o mecanismo pelo qual sociedades desiguais do ponto de vista social e econômico, destinam a maior carga dos danos ambientais às populações de baixa renda, aos grupos sociais discriminados, aos povos étnicos tradicionais, aos bairros operários, às populações marginalizadas e vulneráveis ${ }^{36}$. Esses mecanismos são possíveis devido ao sempre maior intercâmbio econômico e financeiro entre os países, possibilitado pelo mercado globalizado que exporta os danos ambientais de processos industriais, não mais aceitáveis pelos cidadãos de Primeiro Mundo, metabolizando-os socialmente e externalizando seus custos para lugares habitados por populações pobres.

Desconhecer os efeitos colaterais destes processos macroeconômicos sobre o meio ambiente pela conformação de territórios seria maquiar o fenômeno da degradação ambiental e social nos países periféricos. Os países subdesenvolvidos são responsabilizados pela degradação ambiental em seus territórios, esquecendo que ela é a externalização de danos ambientais dos países ricos. A degradação, além de exterminar ecossistemas e sua biodiversidade, afeta a saúde das populações, destruindo o meio ambiente natural e cultural - base para a reprodução social da vida ${ }^{37}$.

As chagas ambientais manifestam-se no uso da terra pela monocultura do agronegócio exportador, espalhando desertos verdes de soja, de cana de açúcar, de eucaliptos com a correspondente exploração de trabalho sazonal em condições infra-humanas; na exploração de minerais gerando poluição e riscos para os ecossistemas e para as populações circunvizinhas; na produção de energia hidroelétrica pela construção de barragens, extinguindo biomas e expulsando pequenos agricultores de suas terras; nos conflitos sociais envolvendo o acesso ao solo urbano para moradia e na localização da poluição industrial e de resíduos tóxicos na proximidade de bairros populares ${ }^{38}$.

Essas formas de devastação ambiental agudizam as disparidades espaciais, contribuindo para o aumento das desigualdades de saúde em todo o mundo. Ante a magnitude desse contexto, a integração da promoção da saúde e da justiça ambiental pode produzir ferramentas conceituais e estratégicas potentes ao enfrentamento do fenômeno, na perspectiva do desenvolvimento humano responsável e da sustentabilidade ambiental ${ }^{39,40}$. 
Nessa direção, e no âmbito dos sistemas de saúde, a literatura nacional e mundial destaca a abordagem da atenção primária como indutora dessas articulações, em conjunto com a participação social ${ }^{41}$. Seu papel é estratégico, pois leva a atenção à saúde o mais próximo possível do local onde as pessoas vivem e trabalham, constituindo o primeiro elo do processo de atenção continuada à saúde. Mais próximas à sua comunidade, as equipes de saúde são dispositivos estratégicos no acionamento das redes e culturas locais, nos processos de participação social, bem como podem propor ações intersetoriais e transdisciplinares no território e em suas conexões com o sistema e demais instâncias públicas e de controle social. Esses aspectos, somados ao nível de cobertura e de resolubilidade da atenção, constituem desafios éticos a serem alcançados no enfrentamento dos determinantes sociais das iniquidades em saúde.

\section{Considerações finais}

Fazer uma leitura bioética da tríade território, ambiente e saúde compreende a adoção de uma visão ecossistêmica de saúde, tendo como categoria central a qualidade de vida socialmente determinada por fatores econômicos, físicos, químicos, biológicos e culturais do ambiente - e seus impactos nos territórios, espaços sociais dos processos de saúde-doença. Essa constatação aponta para a tomada de consciência do paradigma que sustenta as teorias e os modelos de atenção e gestão da saúde como uma exigência ética para os atores envolvidos na organização dos serviços de saúde, pois as ações de promoção, prevenção e vigilância incidem diretamente nos determinantes que afetam a saúde das populações no âmbito da atenção básica.

A proposta do modelo de vigilância em saúde pretende responder a essa preocupação, reorganizando os processos de trabalho e as práticas de atendimento em consonância com as necessidades em saúde do território ambiente da população atendida.
Existem dois grandes desafios éticos para a construção dessa proposta: o primeiro é a construção da vigilância em saúde integrada com a atenção básica como modelo de atenção. Para tanto, faz-se preciso introduzir nos processos de trabalho o método da cogestão e a consequente educação permanente em vista de uma atenção básica e vigilância inseridas nas necessidades em saúde do território ambiente da população atendida. Este é um desafio ético para as equipes e gestores locais, instaurando processos de reflexão e avaliação sobre as práticas cotidianas e consciência dos modelos de atenção que atravessam os processos de trabalho, criando as condições para assumir a corresponsabilidade pelas respostas às necessidades de uma população determinada - este é o desafio ético da relação da saúde com o território entendido como espaço da sociabilidade cotidiana.

O segundo desafio é a construção de políticas públicas intersetoriais que assumam os determinantes sociais da saúde como conformadores do território ambiente da população atendida pelos serviços, no sentido de criar melhores condições para a reprodução social da vida. Para isso, faz-se necessária uma articulação política por parte dos gestores de saúde, visando pactuar ações intersetoriais como, por exemplo, educação inclusiva, geração de emprego e renda, saneamento básico, praças e áreas de lazer, de esporte, iniciativas que parecem não ter muito a ver com saúde, mas que a longo prazo são mais efetivas do que medicamentos e leitos hospitalares para melhorar a saúde da população. Este é o desafio ético da relação da saúde com um macroambiente entendido como condição para a reprodução social da vida.

Esses desafios são éticos, mas também políticos, haja vista dependerem de decisões, articulações e pactuações tanto no nível micro do local do serviço quanto no nível macro de governança e de relação com as redes e ações intersetoriais. Uma bioética que tenha como foco os desafios presentes nas práticas da atenção básica tem que levar em consideração essa dupla dimensão micro do território e a dimensão macro do ambiente em suas relações com a saúde.

\section{Referências}

1. Zoboli ELCP, Fortes PAC. Novas pontes para a bioética: do indivíduo ao coletivo, da alta especialização à atenção básica. Mundo Saúde (Impr.). 2004;28(1):28-33.

2. Robillard HM, High DM, Sebastian JG, Pisaneschi JI, Perritt LJ, Mahler DM. Ethical issues in primary health care: a survey of practioners' perceptions. J Community Health. 1989;14(1):9-17.

3. Mazetto FAP. Pioneiros da geografia da saúde: séculos XVIII, XIX e XX. In: Barcellos C, organizador. A geografia e o contexto dos problemas de saúde. Rio de Janeiro: Abrasco; 2008. p. 17-33. 
4. Santos M. Metamorfoses do espaço habitado. São Paulo: Hucitec; 1988. p. 28.

5. Miranda AC, Barcellos C, Moreira JC, Monken M et al., organizadores. Território, ambiente e saúde. Rio de Janeiro: Fiocruz; 2008.

6. Santos M. A natureza do espaço: técnica e tempo, razão e emoção. $4^{a}$ ed. São Paulo: Edusp; 2006.

7. Nossa PN. Linhas de investigação contemporâneas na geografia da saúde e a noção holística de saúde. In: Barcellos C, organizador. A geografia e o contexto dos problemas de saúde. Rio de Janeiro: Abrasco; 2008. p. 35-62.

8. Samaja JA. A reprodução social e a saúde: elementos teóricos e metodológicos sobre a questão das "relações" entre saúde e condições de vida. Salvador: Editora Casa de Qualidade; 2000.

9. Samaja JA. Epistemología de la salud: reproducción social, subjetividad y transdisciplina. Buenos Aires: Lugar Editorial; 2004.

10. Samaja JA. Op. cit.; 2000. p. 95-6.

11. Junges JR, Zoboli EL. Bioética e saúde coletiva: convergências epistemológicas. Ciên Saúde Colet. 2012;17(4):1054.

12. Junges JR, Selli L. Bioethics and environment: a hermeneutic approach. J Int Bioethique. 2008; 19(1-2):105-19.

13. Bourdieu P. The forms of capital. In: Richardson JG, organizer. Handbook of theory and research for the sociology of education. Westport: Greenwood Press; 1986. p. 241-58.

14. Pattussi MP, Junges JR, Moysés SJ, Sheiham A. Capital social e agenda de pesquisa em epidemiologia. Cad Saúde Pública. 2006;22(8):1525-46.

15. Junges JR. A proteção do meio ambiente na declaração universal de bioética e direitos humanos. Revista Brasileira de Bioética. 2006;2(1):21-38.

16. Ávila-Pires FD. Princípios de ecologia médica. Florianópolis: UFSC; 2000.

17. Minayo MCS. Enfoque ecossistêmico de saúde e qualidade de vida. In: Minayo MCS, Miranda AC, organizadores. Saúde e ambiente sustentável: estreitando os nós. Rio de Janeiro: Fiocruz; 2002. p. 173-89.

18. Minayo MCS. Op. cit. p. 174.

19. Morin E. O método 4 - As ideias: habitat, vida, costumes, organização. Porto Alegre: Sulina; 2001. p. 319.

20. Morin E. Op. cit. p. 282-3.

21. Morin E. O método 3 - O conhecimento do conhecimento. Porto Alegre: Sulina; 1999.

22. Brasil. Ministério da Saúde. Portaria ${ }^{\circ}$ 3.252, de 22 de dezembro de 2009. Aprova as diretrizes para execução e financiamento das ações de Vigilância em Saúde pela União, Estados, Distrito Federal e Municípios e dá outras providências. Diário Oficial da União. 23 dez. 2009;(245):seção I, p. 65-9.

23. Brasil. Ministério da Saúde. Portaria $n^{\circ} 2.488$, de 21 de outubro de 2011. Aprova a Política Nacional de Atenção Básica, estabelecendo a revisão de diretrizes e normas para a organização da Atenção Básica, para a Estratégia Saúde da Família (ESF) e o Programa de Agentes Comunitários de Saúde (PACS). Diário Oficial da União. Brasília 24 out. 2011;(204):seção I, p. 48-55.

24. Mendes EV. Distrito sanitário: o processo social de mudança das práticas sanitárias do sistema único de saúde. São Paulo: Hucitec; 1993.

25. Paim JS. Vigilância da saúde: tendências de reorientação de modelos assistenciais para a promoção da saúde. In: Czeresnia D, Freitas CM, organizadores. Promoção da saúde: conceitos, reflexões e tendências. Rio de Janeiro: Fiocruz; 2003. p. 161-74.

26. Teixeira CF. Promoção e vigilância da saúde. Salvador: Ceps-ISC; 2002.

27. Teixeira CF. Promoção e vigilância da saúde no contexto da regionalização da assistência à saúde no SUS. Cad Saúde Pública. 2002;(18 Suppl):153-62.

28. World Health Organization. Declaração política do Rio sobre determinantes sociais da saúde. Conferência mundial sobre os determinantes sociais da saúde. [Internet]. Rio de Janeiro: WHO; 2011 [acesso 10 maio 2013]. Disponivel: http://www.who.int/sdhconference/declaration/Rio_ political_declaration_portuguese.pdf

29. Brasil. Comissão Nacional sobre os Determinantes Sociais da Saúde. Determinantes sociais da saúde ou por que alguns grupos da população são mais saudáveis que outros? [Internet] Rio de Janeiro: Fiocruz; 2006 [acesso 10 maio 2013]. Disponível: http://www.determinantes.fiocruz.br/ chamada home.htm

30. Buss PM, Pelegrini Filho A. A saúde e seus determinantes sociais. Physis. 2007;17(1):77-93.

31. World Health Organization. Essential environmental health standards in health care. Adams J, Bartram J, Chartier Y, editors. [Internet]. Geneva: WHO; 2008 [acesso 13 abr. 2013]. Disponível: http://whqlibdoc.who.int/publications/2008/9789241547239_eng.pdf

32. Rigotto RM, Augusto LGS. Saúde e ambiente no Brasil: desenvolvimento, território e iniquidade social. Cad Saúde Pública. 2007;23(4 suppl.):S475-85.

33. Acselrad H, Herculano $\mathrm{S}$, Pádua JA, organizadores. Justiça ambiental e cidadania. Rio de Janeiro: Relume-Dumará; 2004.

34. Freitas CM, Porto MF. Saúde, ambiente e sustentabilidade. Rio de Janeiro: Fiocruz; 2006.

35. Acselrad H, Mello CCA, Bezerra GN. O que é justiça ambiental. Rio de Janeiro: Garamond; 2009. p. 160.

36. Freitas CM, Porto MF. Op. cit. p. 91. 
37. Junges JR, Selli L. Bioethics and environment: a hermeneutic approach. J Int Bioethique. 2008;19(1-2):105-19.

38. Junges JR. (Bio)ética ambiental. São Leopoldo: Unisinos; 2004.

39. Masuda JR, Poland B, Baxter J. Reaching for environmental health justice: canadian experiences to an agenda of research, policy and advocacy comprehensive health promotion. Health Promot Int. [Internet]. 2010 [acesso 27 maio 2013]; 25(4): 453-63. Disponível: http://www.problemsinanes. $\mathrm{com} / \mathrm{pt} / \mathrm{re} / \mathrm{pgme} /$

40. Maeseneer MDJ, Sutter MDA, MAS Willems, MLI Van de Geuchte, MSM Billings. Primary health care as a strategy for achieving equitable care: a literature review commissioned by the Health Systems Knowledge Network. [Internet]. 2007 [acesso 19 ago. 2011]. Disponível: http://www. who.int/social_determinants/resources/csdh_media/primary_health_care_2007_en.pdf

41. Mendes EV. Revisão bibliográfica sobre as redes de atenção à saúde. [Internet]. Belo Horizonte: Secretaria de Estado de Saúde de Minas Gerais; 2007 [acesso 30 maio 2013]. Disponível: http://www.saude.es.gov.br/download/REVISAO_BIBLIOGRAFICA_SOBRE_AS_REDES_DE_ ATENCAO_A_SAUDE.pdf

Participação dos autores

José Roque Junges redigiu e Rosangela Barbiani revisou e aperfeiçoou a forma e o conteúdo do artigo.

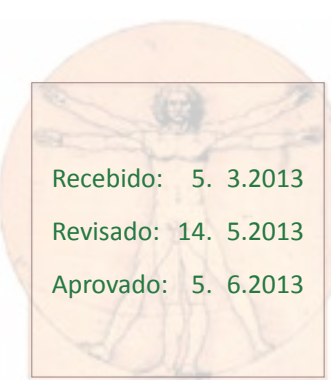

